\title{
IMMUNOPROPHYLAXIS OF VIRAL INFECTIONS IN CHILDHOOD*
}

\author{
Pearay L. Ogra** \\ Buffalo, New York
}

Civilized man discovered the concept of natural immunity long before viruses and bacteria were recognized as the causative agents of infectious diseases. It is particularly fascinating to note that the development of many viral and bacterial vaccines, and the successful control of several infectious diseases preceded the elucidation of the complex defense mechanisms of the host. Although Jenner discovered an effective means of preventing smallpox nearly two centuries ago, it is only in the past decade that the mechanisms of induced immunity are being fully characterized and better understood.

Before the specific aspects of immunzation against viral diseases is discussed in greater detail, an attempt will be made to review briefty the defense mechanisms which are normally present prior to an infection, and those which develop in response to it. The important mechanisms of resistance to infection are listed in Table 1.

\section{Non Specific Immune Mechanisms}

Intact skin and mucous membrane provides a mechanical barrier to the entry of the virus into the host. In

*From the Department of Pediatrics, School of Medicine, State University of New York at Buffalo, and the Virology Laboratory, Childrer's Hospital, Buffalo, N. Y.

* Postal address: Children's Hospital, 219 Bryant Street, Buffalo, New York 14222, U.S.A.
Table 1. Mechanisms of defense against infection

Non-specific

1. Intact skin and mucous membrane

2. Lysozyme

3. Condition of growth :

4. Phagocytosis $\mathrm{pH}$, oxygen tension, temperature

5. Complement

6. "Properidin system" and opsonins

Specific

1. Delayed hypersensitivity

2. Antibody : Scrum

Secretory

addition, lactic acid in the secretions of sweat glands, fatty acids in the sebum, and lysozyme play a role in preventing entry of infectious agents (Raffel 1961).

As living organisms, viruses require optimal conditions of temperature, $\mathrm{pH}$, and oxygenation, for replication in the host tissue. Elevated body temperature, which often accompanies an inflammatory process has the ability to signifcantly dampen the multiplication of many viruses, and recovery is generally impaired when hypothermia is artificially induced. Acid metabolites, lowered $\mathrm{pH}$, and lowered oxygen tension adversely affects the replication of many viruses. Such factors seem to be beneficial to the host in combating the infection (Baron 1964, 1967). 
Phagocytosis is an important defense mechanism against many bacterial and viral infections. Both circulating and fixed phagocytes are in intimate contact with a virus during viremia. The success or failure of certain viruses to multiply within phagocytes is well correlated with the degree of virulence (Bang and Warwick 1960). The mechanism by which phagocytic cells recognize a substance as foreign is not fully understood. Among the factors which enhance phagocytosis are the presence of surfaces against which the cells can trap the antigen particle for ingestion; e.g. surface phagocytosis for pneumococcus, highly polar surface with negative net electrical charge, particulate size of the antigen $(0.02-5 \mu$ range), presence of specific immunoglobulin, and complement.

Complement is a series of nonimmunoglobulin protein macromolecules, which are important to the biologic effects of antigen-antibody interactions. Alterations in the levels of serum complement have been observed in a variety of diseases such as acute glomerulonephritis, rheumatic fever, rheumatoid arthritis, and in the development of cold agglutinins after certain viral infections. However, the function of complement in vivo is still poorly defined. No definite relationship between the frequency of viral infections and the level of complement in the serum have been demonstrated.

The opsonins represent a group of proteins or polypeptides, which have the property of coating small antigenic particles, presumably altering surface properties of antigens, and thereby, promoting phagocytosis ard bacteriolysis. This property is normally associated with specific antibody in an immunized individual. Another protein constituent of normal human serum which together with complement and magnesium ions promotes phagocytosis and bacteriolysis, is termed "properidin". Although the precise nature of properidin is a subject of much controversy, it is generally thought to represent specific antibody, perhaps resulting from stimuli of a variety of antigens in nature.

Interferon is an important antiviral protein produced by virus-infected cells. It is a non-immunoglobulin protein (molecular weight 20,000. 35,000 ). It is stable in a $\mathrm{pH}$ range from $2-11$. Interferon is relatively heat resistant, and non dialyzable. Although the precise mechanism of action is not fully understood, it is believed that establishment of antiviral action within cells requires RNA and protein synthesis. Host cell-interferon interaction induces the formation of new antiviral protein within the cell which appears to determine its eventual antiviral activity. Interferon appears to be species specific in action. However, the antiviral effect seems to be nonspecific, i.e. Interferon produced to one virus is equally effective in limiting replication of other unrelated viruses (Glasgow 1965).

\section{Specific Immune Mechanisms}

Delayed hypersensitivity. Intact mechanism of delayed hypersensitivity is an important aspect of immunity against many bacteria and certain viruses. The cell-bound element of immune response is exemplified by tuberculin sensitivity, and hypersensitivity to drugs. This type of immune response is mediated by sensitized lymphocytes. 
Specifically sensitized lymphocytes have the potential capacity of destroying virus infected cells in a manner similar to homograft rejection. It is also possible that dilayed hypersensitivity may inhibit virus replication by promoting development of antibody containing exudate at the site of initial virus multiplication. It is known that patients with impairment of cell mediated immunity, with or without deficits in circulatory antibody, are unusually susceptible to serious or fatal disease, particularly with those viruses (smallpox, varicella, cytomegalovirus, etc.), in which induction of delayed hypersensitivity may be the principal means of immunity against infection (Kempe 1960, O'Connell 1964). In general, however, infection with other commonly occurring viruses seem to have an apparently normal course of recovery even in the prisence of defective delayed hypersensitivity. Experimental studies have indicated that neonatal thymectomy, and subsequent absence of delayed hypersensitivity, does not impair recovery, and transfer of sensitized lymphocytes fails to induce recovery of mice from lymphocytic choriomeningitis virus infection (Volkert and Larson 1964). In clinical situations patients with defective cellular immunity do not seem to have an increased susceptibility to infections with most enteroviruses.

It is generally assumed that cell mediated element of immune response is triggered by local interaction of antigen with specifically sensitized lymphocytes. This interaction is thought to induce the release of a variety of pharmalogic mediators which inhibit macrophage migration, stimulate DNA synthesis to provoke blast transiormation, and produce cyiotoxic cffects on target cells.

Antibody. The antibody remains the principal, and often the single most effective means of protection against viral disease. This specific immune response of the body, when employed in the form of active inmunization with viral vaccines or passive administration of immunoglobulin provides the effective image of natural protection from infection with a virulent virus.

The antibody activity is associated with a group of heterogeneous proteins, the immunoglobulins. The immunoglobulins are secreted by the lymphoid cells (plasma cells) of human lymphoreticular tissues. Each immunoglobulin molecule is composed of four polypeptide chains, a pair of light chains, Kappa (k) or Lambda $(\lambda)$, and a pair of heavy chains, which are held together by disulfide linkages. The immunoglobulins have class specific determinants associated with their heavy chains. Based on these antigenic differences, the immunoglobulins can be divided into five major classes : $\gamma \mathrm{G}, \gamma \mathrm{A}, \gamma \mathrm{M}, \gamma \mathrm{D}$, and $\gamma \mathrm{E}$. Their physico-chem cal characteristics are listed in Table 2 (Ogra and Karzon 1970).

Owing to the specific properties of the heavy $(\gamma)$ chain, $\gamma \mathrm{G}$ is the only immunoglobulin which is actively transported across the placenta, and constitutes the sole source of protective antibody in the newborn infant.

Recently, it has been demonstrated that the major classes of immunoglobulins present in the serum are also detectable in varying amounts in different secretions bathing the mucosal surfaces of the body. However, the bulk of the immunoglobulin 
Table 2. Physico-chemical products of human immunoglobulins

\begin{tabular}{|c|c|c|c|c|c|}
\hline Property & $\gamma \mathrm{G}$ & $\gamma \mathrm{A}$ & $\gamma M$ & $\gamma \mathrm{D}$ & $\gamma E$ \\
\hline Sedimentation cocfficient & $7 \mathrm{~S}$ & $7 \mathrm{~S}$ & $19 \mathrm{~S}$ & $6 S$ & $8 S$ \\
\hline Molecular weight & 160,000 & $(i 60,000)$ & $(900,000)$ & 160.000 & 200.000 \\
\hline Electrophoretic mobility & $\gamma$ & Slow $\beta$ & $\begin{array}{l}\text { Between } \gamma \\
\text { and } \beta\end{array}$ & $\begin{array}{l}\text { Betwesil } \gamma \\
\text { and } \beta\end{array}$ & Fust $\gamma$ \\
\hline $\begin{array}{c}\text { Rate of synthesis } \\
(\mathrm{mg} / \mathrm{kg} / \mathrm{day})\end{array}$ & 28 & 30 & 6.9 & 2.1 & -* \\
\hline Half-life in serum (days) & 2.3 & 6 & 5 & 2.8 & 2 \\
\hline$\%$ total utilized per day & 3 & 12 & 14 & 28 & - \\
\hline Normal adult level $(\mathrm{mg} / \mathrm{ml})$ & $800-1500$ & $60-490$ & $37-210$ & $0-30$ & Trace \\
\hline
\end{tabular}

*Inadequate data

(From Ogra and Karzon. Ped. Clinics. N. Amer. $17: 385,1970$ ).

in secretions is composed of a nnique form of $\gamma \mathrm{A}$ immunoglobulin. The secretory $\gamma \mathbf{A}$ exists as a dimer of serum $7 \mathrm{~S} \gamma \mathrm{A}$, to which is bound a non-immunoglobulin protein unit variously referred to as secretory piece, or Transport ( $T$ ) piece. The " $T$ " piece usually exists as a portion of the secretory $y \mathrm{~A}$ molecule, although in certain situations it may be found free in the body fluids (Tomasi and Bienenstock 1968). The distribution of secretory $\gamma \mathbf{A}$, secretory piece, and other immunoglobulins in various body fluids is shown in Table 3.

Various studies employing fuorescent labelled type specific antisera to human immunoglobulins have demonstrated immunologically competent plasma cells, producing prodominantiy $\gamma A$ immunoglobulin in various mucosal tissues (Crabbe and Heremans 1967). On the other hand, $\gamma \mathbf{M}$ and $\gamma \mathrm{G}$ producing plasma cells predominate in systemic sites such as spleen and lymph nodes.

It appears that production of secretory (IIS) type $\gamma \mathrm{A}$ immunoglobulin takes place locally in the mucosal interstitial plasma cells (Ogra et. al. 1968, Ogra 1969b). Convincing evidence has accumulated to suggest that the efficacy of viral vaccines to prevent re-infection is largely dete:mined by the optimal development serum as well as secretory antibody responses (Ogra and Karzon 1969 a). Naturally acquired or vaccine induced infections, such as poliomyelitis (Ogra et. al. 1968), measles (Bellanti et al. 1969) rubella (Ogra 1970) mumps, etc., have shown to induce a serum as well as a secretory antibody response. 
Table 3. Distribution of immunoglobulins in body fluids

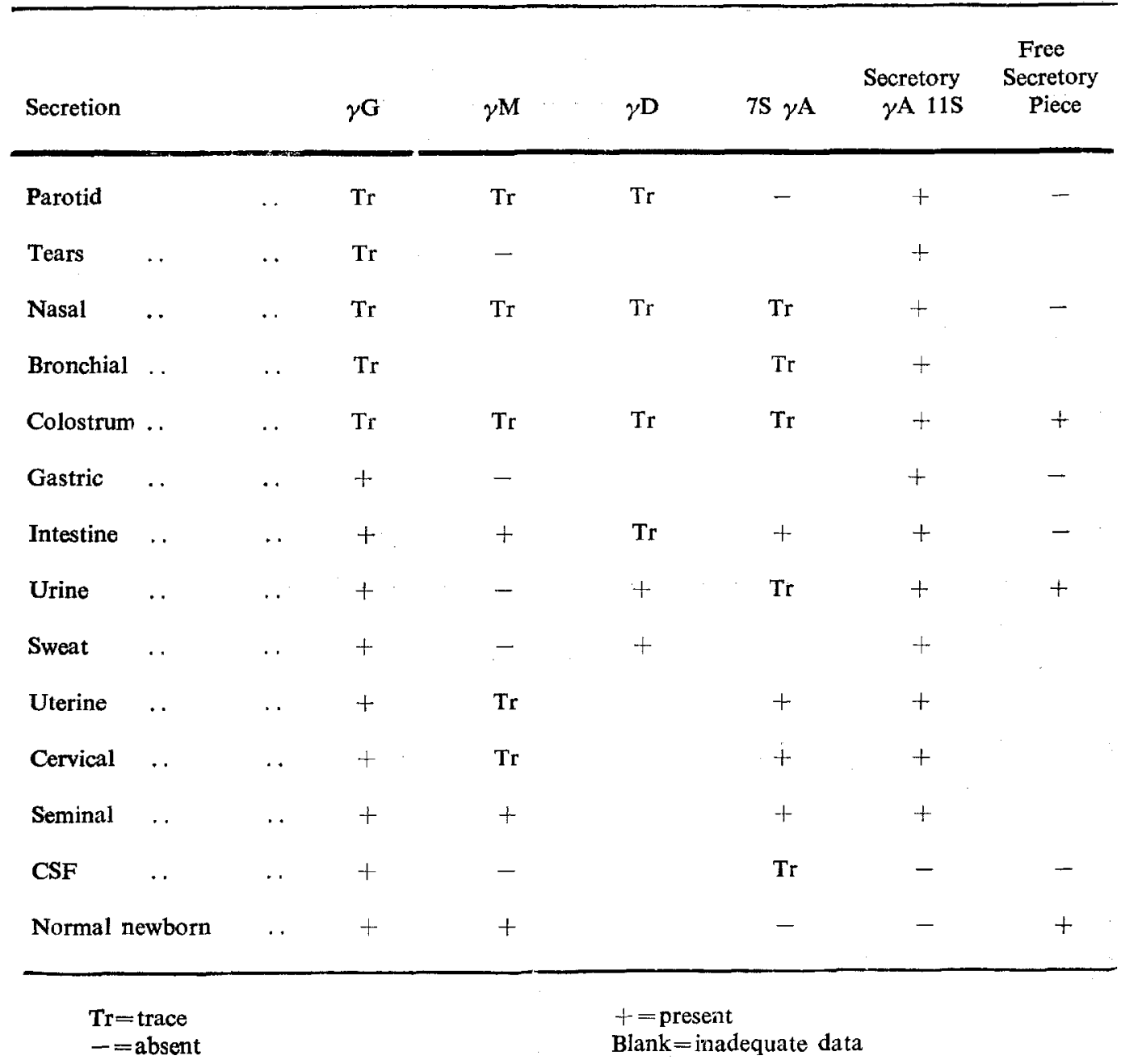

(From Ogra and Karzon. Ped. Clinics. N. Amer. $17:$ 395, 1970).

The immune response observed after parental or oral immunization with live allenuated vaccines are in general quite similar to those observed after naturally acquired infection. On the other hand, following parental immunization with inactivated viral vaccine, although apprcciable serum antibody response is elicited, the secretory antibody responses are conspicuously absent.

However, if such inaclivated viral antigens are administered in high doses locally in a mucosal surface, a secretory antibody response can be elicited, which may or may not be 
associated with a serum antibody response (Ogra and Karzon 1969 a). Secretory antibody response can be expected after infection or immunization with a replicating or non-replicating agent following local or parental route of administration, when adequate antigen mass is available to the mucosal immunocompetent tissues. The use of inactivated vaccine depends mainly on the limited amount of antigen injected for stimulation. On the other hand, with live virus vaccines, a significantly larger antigen mass is attained through self replication, after the initiation of infection. Thus, it is not unexpected that live attenuated virus vaccine induces a more effective response both in the serum and secretions. The various modes by which mucosal immunity can be manifested after immunization is schematically shown in Table 4 .
Recent studics have demonstrated that the secretory antibody in nasopharynx and alimentary tract affords significant protection against reinfection with a virus (Ogra and Karzon 1969a). The degree of resistance against re-infection appiars to be proportional to the level of preexisting secretory antibody as shown in the representative model of poliovirus in Figure 1 .

At high levels of secretory antibody to poliovirus in the nasopharynx, replication of poliovirus in the nasopharynx is almost completely blocked. However, at lower levels of antibody, some replication of virus can go on ( Ogra and Karzon 1970 ).

There appears to be little doubt of the existence of a distinct $m$ :chanism of local immunity which functions as the front line of protection at the

Table 4. Schematic representation of serum and secretory antibody response following immunization with a replicating or a non-replicating antigen.

\begin{tabular}{|c|c|c|c|c|}
\hline \multirow[b]{2}{*}{ Type of Antigen } & \multirow[b]{2}{*}{$\begin{array}{c}\text { Route of } \\
\text { Immunization }\end{array}$} & \multirow[b]{2}{*}{$\begin{array}{l}\text { Serum Ailtibondy } \\
\text { Respunse }\end{array}$} & \multicolumn{2}{|c|}{ Secretory Aistibody Response } \\
\hline & & & $\begin{array}{c}\text { Immunized and } \\
\text { Adjacent Mucosal } \\
\text { Surface }\end{array}$ & $\begin{array}{l}\text { Non-Immunized } \\
\text { Distant Mucosal } \\
\text { Surface }\end{array}$ \\
\hline $\begin{array}{l}\text { Replicating } \\
\text { (live) }\end{array}$ & $\begin{array}{c}\text { Local } \\
\text { Parentcral }\end{array}$ & $\begin{array}{l}+ \\
+\end{array}$ & + & - \\
\hline $\begin{array}{l}\text { Non-replicating } \\
\text { (inactivated) }\end{array}$ & $\begin{array}{c}\text { Local } \\
\text { Parenteral }\end{array}$ & $\overline{+}$ & + & - \\
\hline
\end{tabular}

(From Ogra and Karzon. Ped. Clinics. N. Amer. 17: 385, 1970). 


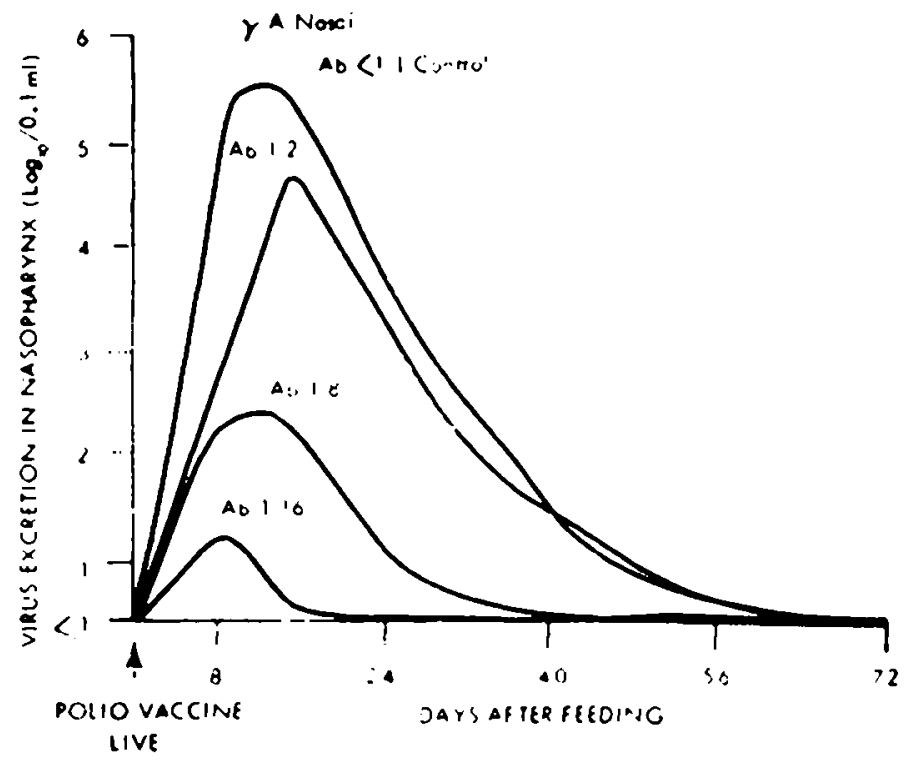

Fig 1. Iffects of varying amounts of pre-existing secretory antibudy on ine replication of live poliovirus.

mucosal sites, where primary replication of virus takes place ( Tomasi 1967). From the clinical point of view the significance of serum and secretory antibody will depend on the natural pathogenesis and target organs of virus infection. For example, the taiget organ in infection with respiratory syncytial virus, influenza virus, parainfluenza virus, and rhinovirus is the mucosa of the respiratory tract. In these situations even substantial levels of serum antibody may not afford protection against re-infection and subsequent clinical disease related to respiratory tract mucosa (Smith et al. 1967 ). However, specific secretory antibody in the respiratory tract may confer significant protection even in the absence of any appreciahle level of scrum antibody (Smith et al. 1966). On the oth:r hand, the target organs involved in paralytic poliomyelitis are those of the central nervous system. It is known that paralytic disease with wild poliovirus can be prevented by scrum antibody which has been induced by parenteral immunization wi'h inactivated (Salk polio vaccine). In such a situation, the alimentary tract does not contain specific secretory antibody, and reinfection of the nasopharynx and alimentary tract with wild poliovirus can be induced at a subsequent re-infection challenge (Ogra et al. 1968 Ogra and Karzon 1969b). 


\section{Specific Viral Vaccines}

\section{Smallpox}

In recent years, as a result of extensive control and eradication programmes sponsored by various national health agencies and the World Health Organization, the incidence of smallpox has sharply declined in many par.s of the world. Protection of the general population against smallpox, through vaccination of infants and re-vaccination of children and adults, has been the nost effective means of defense against the spread of the discase.

The degree of resistance to smallpox varies considerably in different individuals, particulariy in areas where significant reservoirs of endemic disease persist. It is apparent from the studies of Rao (1964) that variation in the natural resistance to infection in the absence of specific antibudy may depend on the age (discrete cases are most often scen in the 5-14 year age group), infecting dose of the virus, physiologic activity of the tissues, and other known non. specific factors, interferon, ctc.

Permanent protection is the rule following natural infection (samllpox or alastrim). Very rarely sccond attacks may occur.

Smallpox vaccine. The bulk of vaccine in use today is the "animal lymph," prepared essentially in a similar manner as it was done 150 years ago, employing the skin of such suscep ible animals as calf and sheep, for the growth of vaccinia virus. The efficacy of smallpox vaccine has never been measured precisely in controlled trials. However, it is generally agreed that the vaccine is highly effec.ive in inducing a specific immune response.
The duration and efficacy of the response depends on the technique of immunization, the ability of the individual to produce specific antibodies, the potency of the vaccine lot used, and the number of vacc nation scars. A high levil of protection is conferred for at least a period of three years after immunization. Vaccination provides appreciable though declining immunily for 10.20 years and may provide protection against a fatal outcome for even longer periods. Dixon has suggested that after single primary inmuniza!ion, the chance of an altack of smallpox is redused to 1 101000 for one yair, 1 to 200 for three years and 1 to 2 for 20 years (1)ixon 1962). Following primary vaccination, hemagglutinating c:omplement fixing, and neutralizing antibodies are demonstrabl: in the serum after 8-12 days.

As a result, vaccination after exposure to smallpox may not always result in protection.

Although circulating antibody provides a high degree of protection against infection, sevire complications of smallpox vaccination have been observed in patients with impaired cell mediated immunity, even in the presence of adequate circulating antibody levels.

The natural portal of entry for the virus is the upper respiratory tract. Virus is usually recovered from the oropharynx from 6-10 days of illness. It secms reasonable to assume that secretory antibody response may be induced in the mucosal sites of replication after natural infection. However, no information is available on the appearance and persistence of local antibody after natural or induced infection with smallpox. 
Vaccine Usage. Primary vaccination may be performed at any age under conditions of exposure. Revaccination should be periormed on entering kindergarten, and every three years. The use of smallpox vaccination is contraindicated in : (1) skin disorders such as eczema or other forms of dermatitis, in the individual considered for vaccination, or in his household contacts.

(2) altered immune states, due to immunosuppressive therapy, (steroids antimetabolites. X-rays, etc.), (3) dysgammaglobulinemia particularly in those immunologic defects which are associated with impairment of cell mediated immunity. e.g. thymic dysplasia, (4) malignancies of reticuloendothelial system, (5) leukemia, and (6) pregnancy (Committec on Infectious Diseases 1970).

Vaccinia Immunoglobulin. Some of the complications of vaccination can be successfully prevented by the administration of gamma globulin prepared from hyper-immune volunteers. Vaccinia immunoglobulin has proved useful in modifying the course of such complications as eczema vaccinatum and inoculation vaccinia. It has, however, little or no effect on progressive vaccinia and post vaccinal encephalopathy. Vaccinia immunoglobulin may also be used if vaccination is undertaken in the contra indicated situations listed above.

Other Vaccines. In addition to animal lymph, vaccinia virus has also been grown in the chorioallantoic membrane of chick embryos (Rivers et al. 1939). Early experience with this vaccine has indicated a lowered degree of immunogenicity. Large scale ficld trials indicated almost $100 \%$ take on primary immunization (Cook et al. 1948). However, the efficacy of this vaccine under heavy smallp $\mathrm{x}$ exposure has not been fully docu. mented.

Vaccinia virus inactivated by form. alin or ultraviolet light has been shown to induce circulating antibody response and modify the subsequent primary take with animal lymph live vaccine. However, protection observed is of a lower order than classic vaccination. Attempts have been made to employ inactivated vaccine as a priming antigen before immunization with live virus in the hope of reducing the complications of live virus immunization (Beunders et al. 1960).

\section{Poliovirus}

The inactivated poliovirus vaccine became available for commercial use in 1955 and the live attenuated poliovirus vaccine was licensed for general use in 1961. A precipitous drop in the incidence of paralytic poliomyelitis became obvious in the United States after the introduction of these vaccines. Approximately $90 \%$ of the reduction was attained after the use of inactivated vaccine alone (Chin et al. 1961).

Inaclived (Salk) Vaccine. This vaccine is prepared by growing poliovirus types in monkey kidney cell cultures and inactivating the infectivity of the virus by formalin treatment. The vaccine is generally used as a trivalent mixture containing poliovirus types 1,2 , and 3. Although the use of inactivated virus (killed) vaccine has been almost completely replaced by live virus vaccines in the United States, the killed vaccine is still widely used in many parts of the world.

Earlier studies have clearly demon- 
strated that circulating antibody induced by parenteral immunization with inactivated vacsine, although able to prevent viremia and spread to the central nervous system, was incapable of preventing nasopharyngeal or alimentary infections. In recent studies it has been demonstrated that parenterally administered inactivated vaccine fails to induce a secretory antibody response in the nasopharyn $x$ and alimentary tract (Ogra et al. 1968). This would explain the susceptibility of alimentary tract to re-infection even in the presence of appreciable levels of circulating antibody.

\section{Live Attenuated ( Subin) Vaccine.}

Live attenuated poliovirus is administered by mouth and initiates alimentary infection in susceptible persons following immunization. The serum antibody response is essentially similar to the response obtained after parenteral immunization with killed virus vaccine (Salk). More significantly, however, following oral immunization wilh live (Sabin) vaccine, the secretory antitody activity against poliovirus is regularly seen in the nasopharynx and alimentary tract (Ogra ct al. 1968),

Thus, the principal advantages of immunization with live virus vaccine over inactivated vaccine are (1) the capacity to inhibit the virus excretion in the immunized individual at a subsequent exposure to wild virus, (2) the immunization of non-immunized individuals through secondary spread of the attenuated virus, thus affording a more efficient herd immunity, (3) more persistent antibody responses in the immunized population, and (4) the ease of administration.

Despite theses obvious advantages, the following siluation should be taken into consideration in the efficient use of live poliovirus vaccines.

Immunization of the Newborn.

Newborn infants, in addition to possessing transplacentally acquired maternal antibody, receive poliovirus antibody in the maternal milk, particularly in areas where the principal means of infint feeding is maternal breast milk. Thus, the ability of the newborn to acquire alimentary tract infection is sufficiently limited. In order tominimize the neutralization of vacine virus by the secretory antibody, it has been suggested that breast feeding be withheld for a few hours before and after the administration of vaccine (Katz and Plothin 1968).

Associution of Paralytic Disease. Association of paralytic disease and administration of poliovirus vaccine has been documented in several reports. However, in the majority of reports, it has not been possible to prove that any individual case was caused by the vaccinc. Unfortunately, no laboratory test is available to provide a definitive answer.

Nevertheless, hased upon epidemiological evidence, it is suggested that a number of cases compatible with vaccine associated paralysis is in the range of one case per four million doses of live poliovirus administered (National Communicable Discases Centre 1968).

Interference. In areas where high levels of infection with other enteroviruses, such as echo, coxsackie, or adenoviruses are present, a significant degree of interference with a successful alimentary infection with poliovirus has been frequently observed (Feldman et al. 1964. The exact mechanism of such influence is not fully understood. 
Such interference effects can be prevented in most areas by administering vaccine during the season when the enteroviruses are not prevalent in the community. However, in poliovirus endemic areas, it is advisable to immunize, particularly the children, routinely, irrespective of the season.

Vaccine Usage. When employing trivalent live attenuated vaccine a three-dose immunization schedule should be started at two to three months of age in conjunction with DPT. The second dose should be given eight weeks later, the third dose should be given eight to twelve months after the second dose. When employing monovalent live vaccine, one dose of each of the three types of live virus vaccine is given at six to eight week intervals beginning at two to three months of age (Advisory Committee on Immunization 1969). A booster dose of trivalant live vaccine is given eight to twelve months after the third dose of monovalent vaccine. A certain number of failures of infection which occur due to interference can possibly be overcome by such schedules of feeding.

In areas where immunization with live vaccine can not be undertaken, immunization may be carried out employing inactivated (Salk) polio vaccine. Four doses of inactivated vaccine should be administered parenterally, three at monthly intervals, and the fourth dose six to twelve months after the third immunizing dose. This schedule can be combined with DPT beginning at one to two months of age. In endemic areas a booster dose of inactivated vaccine is recommended every throe to four years to insure adequate levels of serum antibody (Advisory Committee on Immunization 1969).

\section{Measles}

The incidence of complicatioris which may result after measles, makes this disease one of the most important viral infections of childhood. Neurologic complications may oscur in one of every 500 to 1000 cases (Tyler 1957). The incidence of bacterial complications is also significant, particularly manifesting as otitis media and involvement of the respiratory tract. The highest case fatality rate is among children less than one year old (Karelitz et al. 1959).

Measles infection is a life threatening disease in children with leukemia, malnutrition, cystic fibrosis, immunologic deficiency and tuberculosis. It is well known that after natural infection with measles virus, and less frequently after immunization with live attenuated vaccine, the delayed hypersensitivity to tuberculin is temporarily suppressed. Such tuberculin anergy in patients who were previously tuberculin positive may lead to massive dissemination of active tuberculin lesions, or reactivation of clinically quiescent foci (Karzon and Henderson 1966). A combination of malnutrition and underlying tuberculosis may exp!ain the high mortality rate in measles in the developing countries (Taneja et al. 1962).

Live Attenuated Measles Virus Vaccine. The original Edmonston B and the further attenuated strains of Schwarz and Moraten are widely in use. The vaccine is prepared in tissue cultura using chick embryos or dog kidney for the growth and attenuation of the virus. Parenteral administration of attenuated virus vaccine results in mild measles infection. The 
vaccine induced measles differs from natural infection in having a shorter incubation period, the rash and fever is significantly modified, and the complications are virtually eliminated. Further, the attenuated vaccine strains, although replicating in the systemic lymphoid tissue usually can not be recovered from the blood stream or the respiratory tract. Susceptible children in intimate contact with immunized persons remain free of infection. Following immunization, the antibody is demonstrable in the serum in two weeks and persists in appreciable titres for several years. Vaccinees who have appreciable antibody levels in serum have been found to be fully protected against natural disease. Recently, clinical breakthroughs have been observed in several immunized population groups. Such instances seem to be due to an initial vaccine failure and absence of serum antibody response (Lerman and Gold 1970).

Although live virus induced immunity provides protection against clinical disease, the respiratory tract in many vaccinces may still be susceptible to re-infection. Recent studies have suggested that parenteral administration of live virus vaccine may not always induce secretory antibody response in the nasopharynx and lower respiratory tract, which is the natural portal of entry for live virus (Ogra 1970). Absence of local secretory antibody in such individuals may explain the apparent susceptibility to re-infection.

The reactions to immunization with live attenuated virus can be further diminished by simultaneous administration of measles immune globulin. Under such a practice of immunization the fever rarely exceeds $101^{\circ}$ and the frequency of rash is reduced by approximately 25 to $50 \%$, Although all children who are given measles immunoglobulin at the time of immunization respond with serum antibody production, the responses are generally lower than those who are immunized with live attenuated vaccine alone. It has also been suggested that the duration of antibody persistence may be somewhat lower ( Weibel et al. 1964 ).

If measles immune globulin is used in conjunction in with live virus vaccine, the vaccine should be injected in another arm to permit adequate attachment and penetration of live virus in susceptible cells.

Inactivated Vaccine. The inactivated (killed) measles virus vaccine is prepared from Edmonston's strain grown in primary monkey kidney or chick embryo cell cultures, and inactivated with formalin. The vaccine is partly purified by precipitation on alum. Following parenteral immunization with inactivated vaccine, the antibody titres in serum, although appreciable, are gencrally lower than those observed after natural infection or immunization with live virus (Karzon and Henderson 1966), Most significantly, however, the antibody declines more rapidly, and is undetectable after one year. The serum antibody response elicited after inactivated virus appears to be less efficient than antibody response after natural or induced infection in preventing subsequent infection. Recent studies have demonstrated that although parenteral immunization with live vaccine generally induces a local secretory antibody response in the respiratory tract; however, 
following parental immunization with inactivated vaccine, such secretory antibody response is conspicuously absent (Bellanti et al. 1969 ).

Despite the rapid disappearance of antibody from serum, jmmunization with inactivated virus is often accompanied by a hyperreactive state for a prolonged period, which results in a booster type of response at a subsequent re-infection with live or killed virus.

Vaccine Usage. Inactivated vaccine is generally not recommended for routine immunization. This is because of its poor immunogenicity and some of the serious side effects encountered after exposure to natural disease (discussed later in the scction on immunologic balance).

The live attenuatcd virus vaccine is recommended for general use in all susceptible children. It is most useful to vaccinate susceptible children entering nursery schoool and kindergarten, preferably at about one year of age. Edmonston B strain may be accompanicd by administration of measles immune globulin. Immunoglobulin should not be given with further attenuated vaccine. Live attenuated vaccine can usually prevent disease if given before or on the day of exposure to natural disease. Live virus should not be given to patients with tuberculosis unless they are actively under treatment. The use of live vaccine is contra-indicated in altered immune states, immuno-suppressive therapy, dysgammaglobulinemia, leukemia, and other generalized malignosis. In such situations, one may attempt immunization with inactivated measles vaccine or passive immunization with measles immune globulin as soon as possible after known exposure (Advisory Committee on Immunization 1969).

\section{Mumps}

Mumps is one of the commonest of viral diseases occurring in greatest frequency in school age children. However, 15 to $20 \%$ of cases occur after the onset of puberty. Serious complications are rare in pre-pubertal illness, although aseptic meningitis, meningocephalitis, nerve deafness can occur rarely. On the other hand, in post-pubertal illness, the extremely painful complications of orchitis is reported in 20 to $30 \%$ of males ( Harris et al. 1968 ). However, stcrility is rare. All naturally occurring mumps confers long lasting immunity against re-infection. Second attacks are rarely reported. Approximately $30 \%$ of natural infection are subclinical.

Live Mumps Virus Vaccine. This vaccine is prepared in chick embryo cell culture. Following immunization with attenuated mumps virus vaccine, $78 \%$ of children have responded with the development of appreciable antibody titre. The titres are generally lower than those induced by natural disease. The antibody levels have remained elevated at least four years after immunization. Protection against infection appears to be $100 \%$.

Unlike measles vaccine, mumps virus vaccine does not cause local or general reaction.

Vaccine Usage. Mumps virus vaccine may be used at any age. However, it is advisable not to use the vaccine in children under 12 months of age. The vaccine may be particularly considered in children approaching puberty, and adults, particularly male, who have 
not had clinical mumps parotitis. It is not known whether live attenuated mumps virus vaccine provides protection if it is administered after exposure to natural disease. However, there is no contra-indication to such a use. Until further data are available, it is suggested that immunization with live mumps virus vaccine should not be performed in severe febrile illnesses, hypersensitivity, and altered immune states, and immunologic deficiency diseases (Advisory Committee on Immunization 1969).

\section{Influenza}

Influenza is world wide in distribution. Over the years epidemics have appeared in different parts of the world with a striking periodicity. Outbreaks are most common in the period from carly autumn to late spring. In any epidemic area the peak of infectious cases is reached in three weeks and the course is generally completed in another three to four weeks. Influenza infections are characterized by high morbidity and low mortality. Mortality is particularly high in the elderly and the debilitated.

There are three major types of influenza virus, A, B and C. Epidemics of one or the other type have plagued various parts of the world repeatedly. Epidemics with the same virus type seem to re-occur after an interval of eight to ten years. Available evidence suggests that in a period of ten to twelve years, a given family creates such widespread immunity as to limit the spread of that particular virus type. It is well known that influenza virus is highly mutable. Each virus type is comprised of a finite number of antigens which under the stress of immunity in the population, may undergo spontaneous rearrangement, resulting in a variant form which replaces the previously dominant strain. This variant has the potential for spread and production of disease, provided it is sufficiently distinct from the previous strain to evade the heterologous serum antibody (Zhdanov 1962).

Thus, the development of an effective vaccine has been complicated by the problem of multiple antigenie variants and complex antibody responses. Because of these complica. ting factors, the quality and duration of immunity to influenza virus has not been adequately determined.

Influenza Virus Vaccines. Whenever nation-wide epidemics or infection in a large segment of population is anticipated, it is necessary to revise the existing influenza vaccine formulation in order to include contemporary dominart antigens. The standard influenza virus vaccine is a trivalent inactivated preparation containing all three types of virus which is administered parenterally.

Following subcutaneous administration of the inactivated vaccine, appreciable serum antibody response is demonstrable in eight to ten days. The antibody levels then decline and may be undetectable after a year. Most significantly, immunization with inactivated vaccine by a parenteral route generally fails to induce secretory antibody response in the nasopharynx and respiratory tract. As mentioned previously, the target organs of the disease after infection with influenza virus is the mucosa of the respiratory tract. In view of the suggested protective role of secretory antibody, it is reasonable to conclude that circulating 
antibody in the absence of secretory antibody may afford little or no protection against clinical disease. This would explain the relative inefficiency of the existing inactivated vaccine. Recent investigations have been directed towards development of secretory antibody in the respiratory mucosa by local intranasal immunization with live influenza virus or inactivated influenza virus vaccine. Enormous experimental evidence has accumulated in the past decade which suggest that locally induced antibody to influenza virus may be a better index of resistance against disease than the circulating antibody.

Immunization by a local route seems to hold a significant promise of effective local protection against the disease (Waldman et al. 1969).

Vaccine Usage. Until appreciable protection is provided consistently by the influenza virus vaccines, it is not recommended for routine immunization of healthy adults and children (Advisory Committee on Immunization 1969). Despite its limited effectiveness, the vaccine should be considered for poor risk patients, particularly for chronically debilitated conditions, chronic bronchopulmonary disease, old people with arteriosclerotic complications, etc. The immunization should be carried out in a series of two doses administered subcutaneously six to eight weeks apart.

\section{Rubella}

Rubella is the mildest of the viral infections of childhood. Uneventful recovery is the rule in childhood infections. However, rubella is a disease of major importance because of high incidence of congenital defects in newborn infants whose mothers acquire infection during early pregnancy. The intra-uterine rubella infection is characterized by typical anomalies of deafness, congenital heart disease, cataracts, microcephaly, and mental retardation.

This clinical picture is collectively referred to as the congenital rubella syndrome (Cooper and Krugman 1967). The mechanisms responsible for the teratogenicity of rubella infection in utero are not known. Recent studies have suggested that rubella infection inhibits mitotic processes in cell division and increases the number of chromosomal breaks (Plotkin et al. 1965). It would seem that a disseminated infection of the fetus during the period of organogenesis (first trimester) would interfere with normal evolution of the organs, thus resulting in various forms of malformation.

Following intra-uterine infection, $75 \%$ of women may abort spontaneously. If infection is acquired in the first trimester of pregnancy, incidence of the congenital rubella syndrome in the newborn may be as high as 80 to $90 \%$.

Live Attenuated Rubella Virus Vaccine. The most effective means of preventing rubella infection during pregnancy and subsequent birth of babies with the rubella syndrome would be the widespread use of a safe and effective live virus vaccine. It is hoped that immunization with such a vaccine will eliminate the transmission of virus among children who are the major source of infection for susceptible pregnant women.

Recently, live attenuated rubella has been licensed in the United States and in several Western European countries. Attenuated rubella virus vaccine is prepared by propagation of 
rubelia virus strains indog kidney, duck embryo, African green monkey kidney, or rabbit kidney tissuse cultures. The two commercially available vaccines are HPV-77 prepared in duck embryo or dog kidney and Cendehill-51 prepared in rabbit kidney.

Following immunization with attenuated rubella virus, appreciable serum antibody levels are demonstrable in seven to ten days. The antibody response is generally lower than the response observed after natural infection. Serum antibody levels have decreased only slightly during three years of observation. Although long term protection is likely, its exact duration is yet to be determined. Following parental administration of vaccine, transient pharyngeal shedding of virus has been observed. It is estimated that 30 to $50 \%$ of children immunized in such a way may excrete virus in the nasopharynx for two to three weeks after immunization (Dudgeon et al. 1969). However, there is no evidence of communicability for the shed vaccine virus. Recent investigations have shown that immunization affords protection against illness following either natural exposures or artificial challenge.

It may, however, be pointed out that following such reinfection challenge by the oral pharyngeal route, in approximately $50-70 \%$ of immunized children, replication of virus in the nasopharynx can be frequently demonstrated (Hortmann et al. 1970. The apparent susceptibility of the respiratory tract to infection in children immunized with parenterally administered vaccine appears to be related to poor secretory antibody responses following such a route of immunization (Ogra 1970). Preliminary investigations carried out in the laboratory of the author indicate that although naturally acquired rubella virus infection is always accompanied by appearance of secretory antibody in the nasopharynx, such response is seen only occasionally following parenteral immunization with live attenuated rubella virus vaccine.

Vaccine Usage. Live rubella virus vaccine is recommended for boys and girls in the pre-pubertal age. Vaccine is not recommended for infants less than one year of age. Vaccination of adolescent or adult males is of much lower importance because so few are susceptible. It is not yat determined as to what extent infection of the fetus with attenuated virus may take place. Therefore, immunization of susceptible adolescent or adult females should be carried out anly after pregnancy is ruled out and conception can be effectively prevented during the next two months after immunization.

Immunization of suscep tible pregnant women is contraindicated until more more information is available (Advisory Committee on Immunization 1969).

\section{Concepts of Immunologic Balance in Immunization}

Recently, it has been observed that children previously immunized with parenterally administered inactivated measles virus vaccine when re-immunized with live attenuated measles vaccine develop atypical skin reactions at the site of immunization, manifest a generalized, sometimes fatal, vasculitis, when exposed to natural measles infection ( Scott and Bonanno 1967). This phenomenan 
appears to represent an abnormality of the immune response which results from an inappropriate immunologic stimulus relative to the immunologic response. Similar mechanisms seem to exist in fulminating sepsis, or during immunization with live vaccine in immunologic deficiency diseases, such as the development of vaccinia gangrenosa after smallpox immunization, in patients with impaired cellular immunity. Immunologic imbalance may also be encountered when cell production of immune response may be inappropriate to the stimulus, such as occurs with increased $\gamma \mathrm{E}$ immunoglobulin production in atopy.

In the preceding section, it has been suggested, that in general, immunization with inactivated vaccine administered by a parenteral route selectively stimulates the humoral antibody response with a conspicuous lack of secretory antibody response. Such antibody responses may represent yet another form of immunologic imbalance. The atypical reactions seen after immunization with inactivated measles vaccine appear to be mediated by hypersensitivity (Bellanti et al. 1970). It is not certain whether the manifestations are those of immediate or delayed hypersensitivity. One of the most striking features in these children is the absence of circulating antibody. Vasculitis induced by immunologic mechanisms is characterized by the disposition of immune complexes in the affected tissues. Complexes of $\gamma \mathrm{G}$ immunoglobulinmeasles virus-complement (C'3) have been observed in the atypical skin reactions of measles. On the basis of these observations it has been suggested that immediate hypersensitivity (arthus type of reaction) may be par- tially responsible for such reactions, since such deposits are generally not found in the local sites of delayed hypersensitivity (Bellanti et al. 1969 ).

A similar immunologic difficulty has been observed in infections with respiratory syncytial virus.

This virus is the commonest etiologic agent of bronchiolitis in infants. During experimental trials of parenteral immunization with inactivated respiratory syncytial virus vaccine, it was observed that such immunized infants developed a most serious and ofien fatal form of bronchiolitis when exposed to natural infection (Chanock et al. 1968). This paradoxical situation seems to be partly explained by a similar mechanism which operates in the pathogenesis of atypical reactions to inactivated measles virus vaccine. Following natural infection with respiratory syncytial virus, an immediate recall of serum antibody was speculated which would complex with virus within the respiratory tract leading to immunologic injury to the respiratory mucosa.

Another form of inappropriate immunologic balance may exist in development of paralytic poliomyelitis in children whose tonsils have been previously removed. It is known that recent or remote removal of tonsils and adenoids significantly increases the risk of spinal or bulbar poliomyelitis during epidemics of poliovirus infection. The mechanism by which tonsillectomy modifies the pathogenesis of poliovirus infection is not known, although trauma associated with the tonsillectomy during invasive stage of the disease has been thought to be an important predisposing factor.

Recent studies have demonstrated 
that complete removal of tonsils and adenoids in children immunized with live poliovaccine may deprive such children of a significant source of immunocompetent tissue in the nasopharynx, which may be actively involved in the replication of poliovirus, and the synthesis of specific antibody. In view of the suggested protective role of secretory antibody in the nasopharynx, it appears that deficiency of local antibody as a result of tonsillectomy may permit more extensive virus replication in the nasopharynx, and thus, increase the risk of direct involvement of the central nervous system after an infection with wild poliovirus (Ogra 1970 b).

\section{Conclusion}

It appears that an ideal vaccine would be the one which closely simulates the immunologic events occurring during the course of natural infection. Natural infection through the natural portal of entry seems to induce serum as well as secretory antibody response. Live attenuated vaccine administered orally most closely resembles natural infection in eliciting a balanced immunologic response. However, parenteral immunization with inactivated vaccine may be complicated by unbalanced immune response stimulating the humoral system without any secretory antibody production. Current approaches in immunoprophylaxis of viral disease are thus directed at immune mechanisms which lead to uniform stimulation of only certain components of the immune system. Hopefully, this approach would lead to balanced immunologic responses rather than a situation of altered immunity and hypersensitivity. Further, the success which has been attained with the use of live attenuated vaccine, suggests that the development of local immunity at the primary portal of entry may eventually provide an effective means of eradication of pathogenic virus flora in any community.

\section{References}

Advisory Committec on Immunization. (1969). In Morbidity and Mortality. Wcekly Reports of Communicable Diseases Centre, Atlanta, Ga. $18,43$.

Bang, F. B. and Warwick, A. (1960). Proc. Natn. Acad. Sci. 46, 1065.

Baron, S. (1964). Adv. Virus Res. 10, 39.

Idem. (1967). Modern Trends in Medical Virology. Appleton Century Crofts, New York.

Bellanti, J. A. et al. (1969). New Engl. J. Med. 280, 628.

Idem.(1970). In Conference in Secretory Immunologic System. Vero Beach, Florida, 10-13 December 1969. In press.

Beunders, B. J. W. et al. (1960). Arch. ges. Virusforsch. 10, 382.

Chanock, R. M. et al. (1968). In Purspectives in Virology. Ed. M. Pollard. Volume VI.

Chin, T. D. Y. et al. (1961). Amer. J. Hyg. $74,67$.

Committee on Infectious Diseases. (1970). Annual Report. 16th Edition. American Academy of Pediatrics, Evanston, III.

O'Connell, C. et al. (1964). Ann Intern. Med. 60, 282.

Cook, E. B. M. et al. (1948). Pub. Hlth. Rep. 6, 50 .

Cooper, L. Z. and Krugman, S. (1967). Arch. Ophthal. 71, 434.

Crabbe, P. A. and Heremans, J. F. (1967).

Lab Invest. 16, 112.

Dixon, C. W. et al. (1962). Brit. med.J. 1, 1262.

Dudgeon, J. A. et al. (1969). Ibid. 1, 271.

Feldman, R. A. et al. (1964). Pediatrics, 33, 526.

Glasgow, L. A. (1965). J. Pediat. 67, 104.

Harris, R. W. et al. (1968). Amer. J. Epidemiol. 88, 224.

Horstmann, D. M. et al. (1970). Abstracts of American Pediatric Society Annual Mecting. p. 4. 
Karzon, D. T. and Henderson, D. A. (1966). Adv. Pediat. 14, 121.

Karelitz, S. et al. (1959). J. Pediat. 54, 1.

Katz, M. and Plotkin, S. (1968). J. Pediat. 73, 267.

Kempe, C. H. (1960). Pediatrics, 26, 176.

Krugman, S. et al. (1968). Amer. J. Pub. Hlth. 52, Suppl. 16.

Lerman, S. J. and Gold, Eli. (1970). Socicty for Pediatric Reserch. Annual Meeting, Abstracts. p. 65 .

National Communicable Diseases Centre. (1968). Annual Poliomyclitis Summary.

Ogra, P. L. (1970). Unpublished data.

Ogra, P. L. (1970). American Pediatric

Society. Annual meeting abstracts. p. 1.

Ogra, P. L. et al. (1968). New Eng. J. Med. $279,893$.

Ogra, P. L. and Karzon, D. T. (1969), J. Immunol. 102, 15.

Ogra, P. L. and Karzon, D. T. (1969). J. Immunol. 102, 1423.

Ogra, P. L. and Karzon, D. T. (1970). Ped. Clin. N. Amer. 17, 385.

Plotkin, S. A. et al. (1965). Amer. J. Epidemiol. 81, 71.
Raffel, S. (1961). Immunity, AppletonCentury-Crofts, New York, p. 3.

Rao, A. R. (1964). J. Indian med. Assoc. 43, 224.

Rivers, T. M. et al. (1949). J. exper. Med. 69, 857 .

Scott, T. F. M. and Bonanno, D. E. (1967). New Eng. J. Med. 277, 243.

Smith, C. B. et al. (1966). New Eng. J. Med. 275,1145 .

Smith, C. B. et al. (1967). J. Immunol. 99, 133.

Taneja, P. N. et al. (1962). Amer. J. Dis. Child. 103, 226.

Tomasi, T. B. (1967). Hosp. Pract. 7, 26

Tomsi, T. B. and Bienenstock, J. (1968). J. Adv. Immunol. 9, 1.

Tyler, H. R. (1957). Medicine, 36, 147.

Volkert, M. and Larsen, J. H. (1964). Acta Path. Microbiol. Scand. 60, 577.

Waldman, R. H. et al. (1969). In Conference on Secretary Immunologic System, December 10-13, 1969, Vero Beach, Florida, In press.

Weibet, R. E. et al. (1964). New England J. Med. 270, 172.

Zhdanov, V. M. (1962). J. Hyg. Epidem. 6, 142. 